\title{
Changes in morphological composition of blood in rats under intragastric load with walnut meal
}

\author{
Victor Leonov ${ }^{1}$, Olga Pavlova ${ }^{2 *}$, Olga Gulenko ${ }^{2}$, Maxim Kislov ${ }^{3}$, and Pavel Boriskin ${ }^{1}$ \\ ${ }^{1}$ Private Institution Educational Organization of Higher Education "Medical University "Reaviz", \\ st. Chapaevskaya, 227, Samara, 443099, Russia \\ ${ }^{2}$ Samara State University of Railway Transport, st. Svobody, 2в, Samara, 443066, Russia \\ ${ }^{3}$ I.M. Sechenov First Moscow State Medical University (Sechenov University), st. Trubetskaya, 8, \\ building 2, Moscow, 119991, Russian Federation
}

\begin{abstract}
The basis for the existence of all living organisms is homeostasis. Any living organism is an open dynamic self-regulating system and self-regulation is based on the feedback principle. The use of biologically active substances, for example, plant meal, opens up great possibilities for modulation of physiological processes in the body. Walnut fruit meal also has a rich composition, contains almost all microelements, large amounts of protein as well as carotene, quinones, lecithin, watersoluble vitamins and flavonoids. The aim of the work was to study the adaptive changes in the morphological composition of rat blood to intragastric loading with walnut meal in the form of suspension on distilled water. The experiment was carried out on 60 white laboratory rats. Conclusion: intragastric loading with distilled water suspension of walnut meal in a concentration of $15 \mathrm{mg} / 100 \mathrm{~g}$ body weight of clinically healthy rats was accompanied by an increase in erythrocyte count, hemoglobin concentration and leukocyte count by $6.8 \%, 7.0 \%$ and $9.6 \%$, respectively, compared with the control group animals.
\end{abstract}

\section{Introduction}

Environmental factors, one way or another, affect the body, but these impacts due to automatic self-regulation and mobilization of compensatory-adaptive mechanisms, usually not accompanied by large deviations from the norm, preserving the constancy of the internal environment. But the reserves of living organisms are not limitless and can be depleted over time, resulting in a breakdown of the body's adaptation processes. The basis for the existence of all living organisms is homeostasis. Any living organism is an open dynamic self-regulating system, and self-regulation is based on the principle of feedback [1, $2]$.

Thus, homeostasis is the organism's ability to maintain the constancy of the internal environment and the main features of its inherent organization despite the variability of the external environment and the action of internal disturbing factors, i.e. it is the organism's hereditarily fixed adaptations to the usual environmental conditions [3-5]. The use of

*Corresponding author: casiopeya13@mail.ru 
biologically active substances, such as vegetable meal, offers great opportunities for modulating physiological processes in the body. In general, meal is a by-product of oil extraction production, obtained after oil extraction from vegetable raw materials by extraction with organic solvents $[3,5]$.

As a rule, biologically active substances from natural raw materials increase body resistance, facilitate clinical course of many ecologically determined diseases and practically have no negative side effects. At present, an intensive search for new biologically active substances - antioxidants capable of maintaining homeostasis is underway. Plants containing such compounds as flavonoids, phenylpropanoids, coumarins and other biologically active substances deserve special attention as sources of meal. The use of plant flavonoids improves the clinical course of many environmentally caused diseases and has practically no negative side effects $[4,5]$.

Walnuts fruits are characterized by rich composition and contain lipids (triglycerides of fatty acids, phospholipids, lecithin, sterols, etc.), nitrogenous substances, carbohydrates (sugars, starch, cellulose, etc.), organic acids, phenolic compounds (hydroxycinnamic tannins, hydroxycinnamic acids, gallic acid, ellagic acid, flavonols, etc.). ), organic acids, phenolic compounds (hydrolysable tannins, hydroxycinnamic acids, gallic acid, ellagic acid, flavonols, etc.), vitamins (fat- and water-soluble), micro- and macro-elements $[6,7$, 8]. Walnut kernels have an astringent taste due to the high content of phenolic compounds with anti-cancer, anti-mutagenic and anti-inflammatory effects. These include hydrolysable tannins (they account for $60.80 \%$ of the total amount of phenolic compounds), flavonols $(24.7 \%)$, hydroxybenzoic acids and their derivatives $(12.5 \%)$, hydroxycinnamic acids and their derivatives $(1 \%)$. The kernels also contain procyanidins, catechins, quercetin, and ferulic acid [9-11].

Ascorbic acid and yuglon are especially rich in the green pericarp of walnuts. Juglone (5-oxy-1,4-naphthoquinone) is a natural antibiotic found in all parts of the walnut with high bactericidal activity. Yuglon also inhibits the activity of phosphatidylinositol-3-kinase, indicating its anticoncertogenic properties, with no toxicity common to other cytostatics $[12,13]$.

Walnut meal also has a rich composition, it contains almost all microelements, large amounts of protein, as well as carotene, quinones, lecithin, water-soluble vitamins (A, B1, $\mathrm{B} 2, \mathrm{~B} 3, \mathrm{~B} 12, \mathrm{C}, \mathrm{K}, \mathrm{E}, \mathrm{PP})$ and flavonoids, and therefore is a promising food product for animals and humans. However, its effect on the body at the moment is not studied enough [14].

Thus, the aim of the work is to study the adaptive changes in the morphological composition of rat blood to intragastric loading with walnut meal in the form of suspension on distilled water.

The main objective of our study was to analyze the morphological composition of the blood of rats of the control group and the animals receiving as an additional load intragastric suspension of walnut for 30 days.

\section{Materials and methods}

The experiment was carried out on 60 white laboratory rats (males) weighing 190-210 g, which were divided equally into control and experimental groups.

Rats of the control group received $1 \mathrm{ml}$ of distilled water daily for 30 days as an additional load intragastrically. Animals of the experimental group received a daily intragastric suspension of walnut meal at a dose of $15 \mathrm{mg} / 100 \mathrm{~g}$ of animal weight in $1 \mathrm{ml}$ during the same period. The suspension was prepared in distilled water.

Blood sampling from rats was performed from the tail according to the conventional technique. Blood was analyzed in animals before the experiment, and on the first, third, 
fifth, seventh, tenth, fifteenth, twentieth, twenty-fifth and thirtieth days of the experiment. Rats were kept in the vivarium, with free access to water and food. The blood of the animals was determined by standard methods: number of erythrocytes, hemoglobin concentration, number of leukocytes and leukocytic formula [15].

\section{Results of the study}

The general condition and behavior of the animals receiving the walnut meal suspension did not differ from the rats of the control group. The animals were active, intake of water and food without any peculiarities, and natural excretions were not disturbed.

The study of the reaction of the morphological composition of blood to the walnut meal suspension

showed that the erythrocyte content (Fig. 1) and hemoglobin concentration (Fig. 2) in the animals of the experimental group significantly increased depending on the duration of the meal administration to the rats.

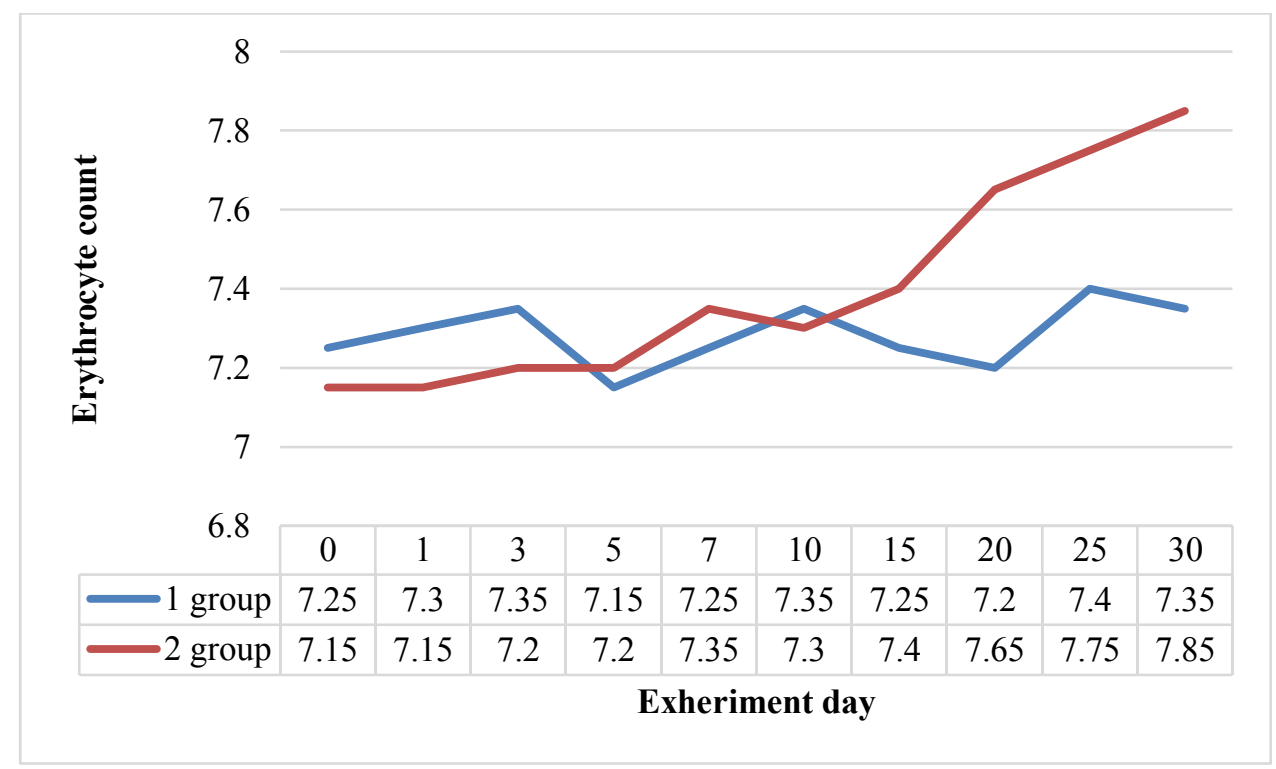

Fig. 1. Dynamics of erythrocyte count (M-1012/1) in blood of rats in norm and against loading with walnut meal.

Thus, on the 30 days of the experiment the number of erythrocytes in the blood of the animals receiving the walnut meal suspension was $6.8 \%$ higher compared with the rats of the control group.

Descriptive statistics of the number of erythrocytes in rats receiving walnut meal intragastrically are presented in Table 1. 
Table 1. Dynamics of erythrocyte count in the blood of rats treated with walnut meal.

\begin{tabular}{|c|c|c|c|c|c|c|c|c|c|}
\hline Day & $\mathbf{N}$ & $\begin{array}{c}\mathbf{M} \\
\mathbf{M} 10^{12} \text { /л }\end{array}$ & $\begin{array}{c}\text { Мe } \\
\text { M } 12 \text { /л }\end{array}$ & Min & $\operatorname{Max}$ & 25 Per & 75 Per & 10 Per & 90 Per \\
\hline 0 day & 30 & 7,153333 & 7,150000 & 6,100000 & 8,300000 & 6,500000 & 7,700000 & 6,400000 & 7,900000 \\
\hline 1 day & 30 & 7,160000 & 7,150000 & 6,100000 & 8,200000 & 6,500000 & 7,700000 & 6,300000 & 7,900000 \\
\hline 3 day & 30 & 7,163333 & 7,200000 & 5,800000 & 8,200000 & 6,700000 & 7,600000 & 6,350000 & 7,900000 \\
\hline 5 day & 30 & 7,170000 & 7,200000 & 6,700000 & 7,800000 & 6,900000 & 7,400000 & 6,750000 & 7,550000 \\
\hline 7 day & 30 & 7,220000 & 7,350000 & 5,600000 & 8,200000 & 6,700000 & 7,800000 & 6,100000 & 8,000000 \\
\hline 10 day & 30 & 7,336667 & 7,300000 & 6,100000 & 8,300000 & 6,900000 & 7,900000 & 6,500000 & 8,150000 \\
\hline 15 day & 30 & 7,416667 & 7,400000 & 6,200000 & 8,300000 & 7,100000 & 7,900000 & 6,600000 & 8,200000 \\
\hline 20 day & 30 & 7,533333 & 7,650000 & 6,100000 & 8,600000 & 7,300000 & 7,900000 & 6,300000 & 8,400000 \\
\hline 25 day & 30 & 7,636667 & 7,750000 & 6,100000 & 8,500000 & 7,300000 & 8,200000 & 6,750000 & 8,300000 \\
\hline 30 day & 30 & 7,746667 & 7,800000 & 6,400000 & 8,800000 & 7,300000 & 8,200000 & 6,950000 & 8,500000 \\
\hline
\end{tabular}

According to the data presented, intragastric loading for 30 days with walnut meal promotes an increase in the number of red blood cells in the peripheral blood of rats.
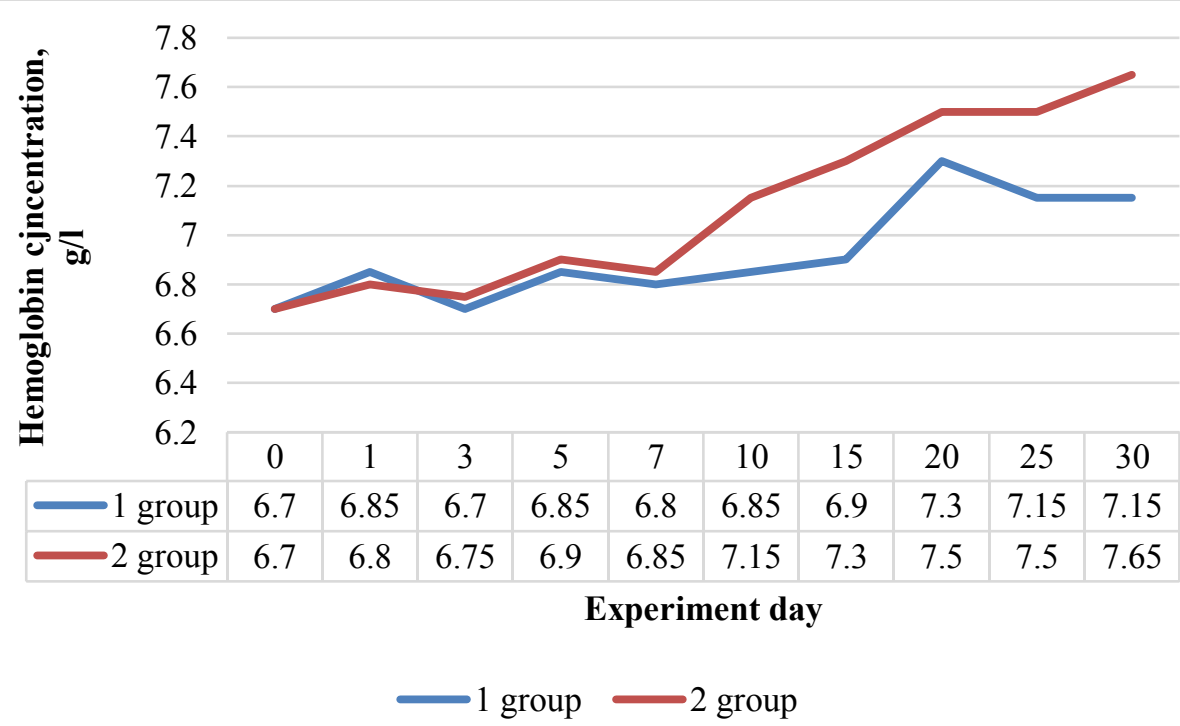

Fig. 2. Dynamics of hemoglobin concentration $(\mathrm{g} / \mathrm{l})$ in blood of rats in norm and against the background of walnut meal loading. 
The concentration of hemoglobin in animals receiving walnut meal intragastrically in the form of suspension at the end of the experiment was higher than in the control by $7.0 \%$.

The array of obtained values of hemoglobin concentration in the blood of the rats of the experimental group is shown in Table 2.

Table 2. Dynamics of hemoglobin concentration in the blood of rats treated with walnut meal.

\begin{tabular}{|c|c|c|c|c|c|c|c|c|c|}
\hline Day & $\mathbf{N}$ & $\begin{array}{c}\mathbf{M} \\
\mathrm{g} / \mathrm{l}\end{array}$ & $\begin{array}{c}\mathbf{M e} \\
\mathrm{g} / \mathrm{l}\end{array}$ & $\mathbf{M i n}$ & $\mathbf{M a x}$ & $\mathbf{2 5}$ Per & $\mathbf{7 5}$ Per & $\mathbf{1 0}$ Per & $\mathbf{9 0 ~ P e r}$ \\
\hline 0 day & 30 & 6,810000 & 6,700000 & 5,800000 & 8,100000 & 6,300000 & 7,300000 & 6,100000 & 7,750000 \\
\hline 1 day & 30 & 6,820000 & 6,800000 & 5,800000 & 7,900000 & 6,300000 & 7,300000 & 6,100000 & 7,750000 \\
\hline 3 day & 30 & 6,850000 & 6,750000 & 6,100000 & 7,900000 & 6,400000 & 7,300000 & 6,200000 & 7,550000 \\
\hline 5 day & 30 & 6,940000 & 6,900000 & 6,100000 & 7,900000 & 6,500000 & 7,300000 & 6,200000 & 7,800000 \\
\hline 7 day & 30 & 6,963333 & 6,850000 & 6,100000 & 7,900000 & 6,500000 & 7,400000 & 6,150000 & 7,750000 \\
\hline 10 day & 30 & 7,080000 & 7,150000 & 6,100000 & 7,900000 & 6,700000 & 7,500000 & 6,350000 & 7,800000 \\
\hline 15 day & 30 & 7,206667 & 7,300000 & 6,100000 & 8,200000 & 6,800000 & 7,700000 & 6,250000 & 7,900000 \\
\hline 20 day & 30 & 7,296667 & 7,500000 & 6,100000 & 8,400000 & 6,700000 & 7,800000 & 6,250000 & 8,050000 \\
\hline 25 day & 30 & 7,360000 & 7,500000 & 6,100000 & 8,100000 & 6,800000 & 7,800000 & 6,550000 & 7,900000 \\
\hline 30 day & 30 & 7,420000 & 7,650000 & 6,200000 & 8,400000 & 6,900000 & 7,900000 & 6,350000 & 8,100000 \\
\hline
\end{tabular}

With regard to hemoglobin concentration, a trend similar to the number of erythrocytes in the blood of rats of the experimental group was noted.

At the end of the experiment in the blood of rats against intragastric load with walnut meal, the number of leukocytes was $9.6 \%$ higher than in the control (Fig.3).

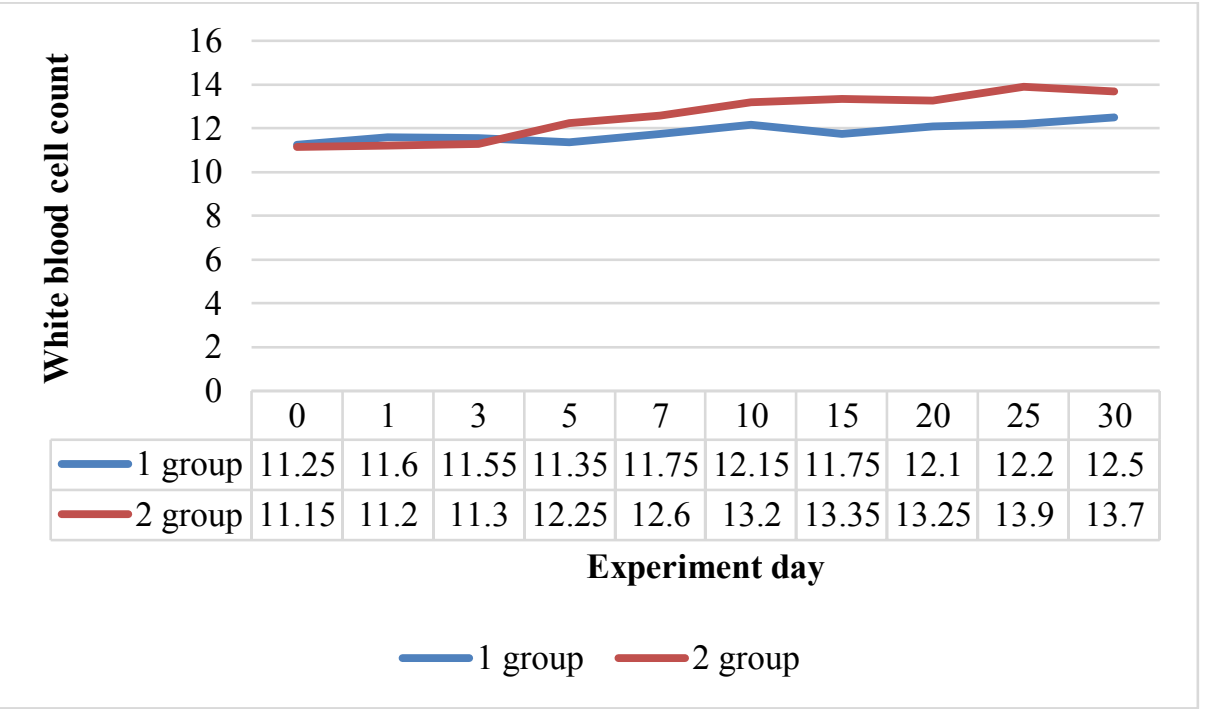

Fig. 3. Dynamics of leukocyte number (M-109/1) in blood of rats in norm and against the background of walnut meal loading. 
The variation in the numerical values of the number of leukocytes in the blood of rats in the experimental group is shown in Table 3.

Table 3. Dynamics of leukocyte count in the blood of rats treated with walnut meal.

\begin{tabular}{|c|c|c|c|c|c|c|c|c|c|}
\hline Day & $\mathbf{N}$ & $\begin{array}{l}\text { M } \\
\text { Г/л }\end{array}$ & $\begin{array}{l}\text { Me } \\
\Gamma / ת\end{array}$ & Min & Max & 25 Per & 75 Per & 10 Per & 90 Per \\
\hline 0 day & 30 & 11,10000 & 11,15000 & 9,60000 & 12,70000 & 10,60000 & 11,60000 & 10,15000 & 12,40000 \\
\hline 1 day & 30 & 11,30000 & 11,20000 & 10,10000 & 13,20000 & 10,60000 & 11,90000 & 10,25000 & 12,70000 \\
\hline 3 day & 30 & 11,40000 & 11,30000 & 10,10000 & 12,80000 & 10,60000 & 12,10000 & 10,25000 & 12,70000 \\
\hline 5 day & 30 & 12,10000 & 12,25000 & 10,10000 & 13,90000 & 11,20000 & 12,80000 & 10,60000 & 13,50000 \\
\hline 7 day & 30 & 12,80000 & 12,60000 & 11,10000 & 14,80000 & 11,80000 & 13,80000 & 11,40000 & 14,25000 \\
\hline 10 day & 30 & 13,30000 & 13,20000 & 11,20000 & 14,80000 & 12,70000 & 14,40000 & 11,75000 & 14,70000 \\
\hline 15 day & 30 & 13,50000 & 13,35000 & 11,40000 & 15,80000 & 12,70000 & 14,30000 & 11,95000 & 15,10000 \\
\hline 20 day & 30 & 13,60000 & 13,25000 & 11,30000 & 15,30000 & 13,10000 & 14,60000 & 12,25000 & 14,85000 \\
\hline 25 day & 30 & 13,80000 & 13,90000 & 11,10000 & 15,50000 & 13,50000 & 14,80000 & 11,85000 & 15,20000 \\
\hline 30 day & 30 & 13,60000 & 13,70000 & 11,10000 & 15,20000 & 13,10000 & 14,30000 & 12,35000 & 14,90000 \\
\hline
\end{tabular}

In the experiment a statistically significant increase in leukocytes within the physiological norm in animals against the background of intragastric load with walnut meal was established.

When studying the leukocyte formula during the experiment, no statistically significant fluctuations of leukocyte forms were found in rats of control and experimental groups. Fluctuations in the number of leukocytes in rats of both groups during the experiment occurred within minimal and statistically insignificant limits.

\section{Conclusions}

Intragastric loading with distilled water suspension of walnut meal in a concentration of 15 $\mathrm{mg} / 100 \mathrm{~g}$ body weight of clinically healthy rats was accompanied by a $6,8 \%, 7,0 \%$ and 9,6 $\%$ increase of erythrocyte number, haemoglobin concentration and leucocyte number in comparison with the control group animals, respectively. The absence of deviations in the number of eosinophils in the blood of the experimental group rats compared with the control indicates hypoallergenicity of walnut meal.

\section{References}

1. J. McFarland, J. Michael, M.P. Wenderoth, H. Modell, A. Wright, W. Cliff, FASEB J., 26(720.4) (2012) [Google Scholar]

2. S. Blanco, R. Hernandez, G. Franchelli, M.M. Ramos-Alvarez M.A. Peinado, Nitric Oxide, 62, 32-43 (2017)

3. J. McFarland, J. Michael, M.P. Wenderoth, H. Modell, A. Wright, W. Cliff, FASEB J., 28(531.13) (2014) [Google Scholar]

4. H.A. Woods, J.K. Wilson, Trends Ecol. Evol., 28, 283-289 (2013) [PubMed] [Google Scholar]

5. N.V. Beloborodova, A.Y. Olenin, N.I. Fedotcheva, V. Shubina, V.V. Teplova, Crit. 
Care, 16(Suppl. 3), 26 (2012)

6. A. Croitoru, D. Ficai, L. Craciun, A. Ficai, E. Andronescu, Curr. Pharm. Des., 29 (2019)

7. D. Hayes, M.J. Angove, J. Tucci, C. Dennis, Crit. Rev. Food Sci. Nutr., 56(8), 1231-41 (2016)

8. D.J. Baer, S.K. Gebauer, J.A. Novotny, 146(1), 9-13 (2016) [PubMed] [Google Scholar]

9. A.M. Brennan, L.L. Sweeney, X. Liu, C.S. Mantzoros, Obesity, 18(6), 1176-1182 (2010) [PMC free article] [PubMed] [Google Scholar]

10. P.M. Kris-Etherton, The Journal of Nutrition, 144(4 Suppl.), 547S-54S (2014) [PubMed] [Google Scholar]

11. D.L. Katz, A. Davidhi, Y.Y. Ma, et al., J. Am. Coll. Nutr., 31, 415-423 (2012) [PMC free article] [PubMed] [Google Scholar]

12. C.E. O’Neil, T.A. Nicklas, V.L. Fulgoni, Nutrients, 7, 595-607 (2015) [PMC free article] [PubMed] [Google Scholar]

13. V. Njike, R. Ayettey, P. Petraro, et al., BMJ Open Diabetes Res. Care, 3, e000115 (2015) [PMC free article] [PubMed] [Google Scholar]

14. S, Kranz, A.M. Hill, J.A. Fleming, et al., J. Hum. Nutr. Dietetics, 27, 247-254 (2014) [PubMed] [Google Scholar]

15. D.W. Greening, K.M. Glenister, R.L. Sparrow, R.J. J. Proteomics, 73, 386-395 (2010) 